\title{
Unruptured pregnancy in non-communicating rudimentary horn of uterus: a case report
}

\author{
Dahiya Sonika, Mukherjee Shobha*
}

Department of Obstetrics and Gynecology, Rohilkhand Medical College and Hospital, Bareilly, U.P., India

Received: 19 June 2015

Revised: 24 June 2015

Accepted: 11 July 2015

\author{
*Correspondence: \\ Dr. Mukherjee Shobha, \\ E-mail: shosa@rediffmail.com
}

Copyright: () the author(s), publisher and licensee Medip Academy. This is an open-access article distributed under the terms of the Creative Commons Attribution Non-Commercial License, which permits unrestricted non-commercial use, distribution, and reproduction in any medium, provided the original work is properly cited.

\begin{abstract}
Pregnancy in a non-communicating rudimentary horn of a uterus is rare. It's incidence is 1 in 76,000 pregnancies. It is treated as an ectopic pregnancy. Most of the times it is diagnosed after rupture in the late $2^{\text {nd }}$ trimester. Here we present a case, where diagnosis is made prior to the rupture
\end{abstract}

Keywords: Non-communicating rudimentary horn, Unruptured

\section{INTRODUCTION}

The incidence of uterine malformations is estimated to be $3-5 \%$ of the general population. A unicornuate uterus is one which has a single horn. Approximately $65 \%$ of women with a unicornuate uterus also have a second small rudimentary horn, which is having a functioning endometrium but is isolated or non-communicating. Pregnancy can occur in a non-communicating arm by transperitoneal migration of the fertilized ovum from the contralateral side. ${ }^{1}$ This is rare and occurs in 1:76,000 pregnancies and is treated as an ectopic pregnancy. ${ }^{2}$ Uterine rupture occurs in $89 \%$ of the cases by the end of the second trimester. Diagnosis prior to rupture is unusual and requires high index of suspicion. We present a rare case of an unruptured pregnancy in the noncommunicating rudimentary horn of uterus.

\section{CASE REPORT}

A 26 year old lady married for 10 years $\mathrm{G}_{4} \mathrm{P}_{1}+{ }_{2} \mathrm{~L}_{1}$ with previous caesarean section at $4 \frac{1}{2}$ months of amenorrhoea presented to us with complaints of painless spotting per vaginum. Her previous caesarean section was for breech presentation and she had previous two spontaneous first trimester abortions. Her vitals were stable. On perabdominal examination-Previous vertical scar of previous section was seen and uterus was enlarged to 18 weeks size with no scar tenderness and with external ballotment present. Per speculum examination revealed minimal blood mixed discharge. On pervaginum examination os was closed.

USG revealed a 17 weeks intrauterine fetal demise with no signs of rupture of previous uterine scar. A decision for termination of pregnancy was taken by intracervical Foley's catheter insertion. During the USG guided procedure, there was considerable difficulty in inserting the catheter and also inflating the balloon. Therefore, the procedure was abondened and decision of laparotomy was taken keeping in mind the possibility of pregnancy in rudimentary horn of uterus. Intraoperative findings revealed the pregnancy in the right unruptured rudimentary horn of uterus. The right round ligament, fallopian tube and ovarian ligament were attached to the lateral aspect of this mass. Resection of this rudimentary horn along with right tube and ovary was done since both were closely attached to this mass. The postoperative period was uneventful and patient was discharged on the tenth post operative day after suture removal. 


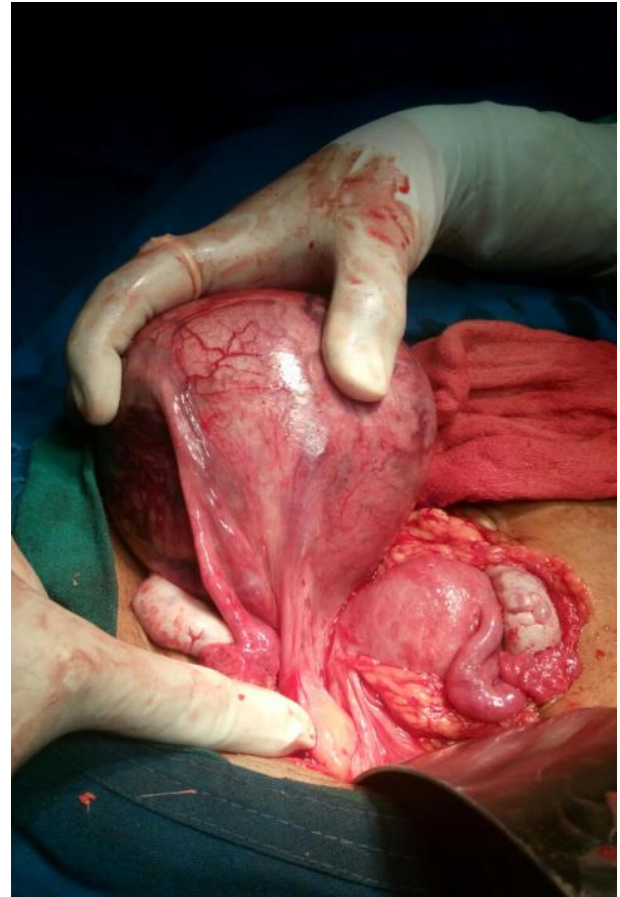

Figure 1: Intraoperative findings showing pregnancy in non-communicating, rudimentary horn of the uterus on right side and showing attachment of ovarian ligament, round ligament and fallopian tube on rudimentary horn

\section{DISCUSSION}

Pregnancy in a non-communicating rudimentary horn of unicornuate uterus is rare and treated as an ectopic pregnancy because most of the times it ruptures in $2^{\text {nd }}$ trimester with disasterous consequences. ${ }^{3}$ Diagnosis prior to rupture is rare and can be made by USG or MRI. Tsafrir et al outlined a set of criteria for diagnosing pregnancy in rudimentary horn. ${ }^{4}$ They are:

1. A pseudopattern of asymmetric bicornuate uterus.
2. Absent visual continuity tissue surrounding the gestation sac and uterine cervix.

3. Presence of myometrial tissue surrounding gestational sac.

In our case, USG was unable to diagnose the condition but a high index of clinical suspicion namely previous caesarean section for breech presentation which pointed towards uterine malformation and inability to instill the foley's catheter freely into uterine cavity, were helpful in diagnosing the condition before the disasterous occurrence of rupture and shock.

Funding: No funding sources

Conflict of interest: None declared

Ethical approval: Not required

\section{REFERENCES}

1. Panayotiditis C, Abdel-Fattah M, Leggot M. Rupture of rudimentary horn of a unicornuate uterus at 15 weeks gestation. J obstet Gynaecol. 2004, 24:323324.

2. ChenCheng, Weiwei Tang, Lei Zhang, Mei Luo et al. Unruptured pregnancy in a non-communicating rudimentary horn at 37 weeks with a live fetus: A case report. Journal of Biomedical research. 2015;29(1):83-6.

3. Jin Woo Shin, Hai Joong Kim. Case of live birth in a non communicating rudimentary horn pregnancy: $\mathbf{J}$ obstet Gynaecol Res. 2005,31:329-31.

4. Tsafrir A, Rojansky N, Sela HY, et al. Rudimenatry horn pregnancy: first trimester prerupture sonographic diagnosis and confirmation by MRI. J ultrasound Med. 2005;24:219-23.

Cite this article as: Sonika $\mathrm{D}$, Shobha $\mathrm{M}$.

Unruptured pregnancy in non-communicating rudimentary horn of uterus: a case report. Int J Reprod Contracept Obstet Gynecol 2015;4:1244-5. 